\title{
IMPLEMENTATION OF AN AGRICULTURAL ENVIRONMENTAL INFORMATION SYSTEM (AEIS) FOR THE SANJIANG PLAIN, NE-CHINA
}

\author{
Q. Zhao ${ }^{\text {a, c,* }}$, S. Brocks ${ }^{\text {a }}$, V. Lenz-Wiedemann ${ }^{\text {a, c }}$, Y. Miao ${ }^{\text {b, c }}$, R. Jiang ${ }^{\text {b }}$, X. Chen ${ }^{\text {b, c }}$, F. Zhang ${ }^{\text {b }}$, and G. Bareth ${ }^{\text {a, c }}$ \\ ${ }^{a}$ Institute of Geography (GIS \& Remote Sensing Group), University of Cologne, 50923 Cologne, Germany - \\ zhaoquanying@gmail.com, (g.bareth, sebastian.brocks, victoria.lenz)@uni-koeln.de \\ ${ }^{\mathrm{b}}$ Department of Plant Nutrition, China Agricultural University, Beijing 100094, China - \\ (ymiao, rfjiang, chenxp, zhangfs)@cau.edu.cn \\ ${ }^{c}$ ICASD - International Center for Agro-Informatics and Sustainable Development (www.icasd.org)
}

KEY WORDS: GIS, Spatial, Decision Support, Modelling, Agriculture, Environment, Farming

\begin{abstract}
:
The Sino-German Project between the China Agricultural University and the University of Cologne, Germany, focuses on regional agro-ecosystem modelling. One major focus of the cooperation activity is the establishment of joint rice field experiment research in Jiansanjiang, located in the Sanjiang Plain (Heilongjiang Province, north-eastern part of China), to investigate the different agricultural practices and their impact on yield and environment. An additional task is to set-up an Agricultural Environmental Information System (AEIS) for the Sanjiang Plain (SJP), which covers more than $100000 \mathrm{~km}^{2}$. Research groups from Geography (e.g. GIS \& Remote Sensing) and Plant Nutrition (e.g. Precision Agriculture) are involved in the project. The major aim of the AEIS for the SJP is to provide information about (i) agriculture in the region, (ii) the impact of agricultural practices on the environment, and (iii) simulation scenarios for sustainable strategies. Consequently, the AEIS for the SJP provides information for decision support and therefore could be regarded as a Spatial Decision Support System (SDSS), too. The investigation of agricultural and environmental issues has a spatial context, which requires the management, handling, and analysis of spatial data. The use of GIS enables the capture, storage, analysis and presentation of spatial data. Therefore, GIS is the major tool for the set-up of the AEIS for the SJP. This contribution presents the results of linking agricultural statistics with GIS to provide information about agriculture in the SJP and discusses the benefits of this method as well as the integration of methods to produce new data.
\end{abstract}

\section{INTRODUCTION}

The Sino-German project between the China Agricultural University (CAU), Beijing, and the University of Cologne, Germany, focuses on regional agro-ecosystem modeling. Since 2007, research groups from Geography (e.g. GIS \& Remote Sensing) and Plant Nutrition (e.g. Precision Agriculture) are involved in the project. The International Center for AgroInformatics and Sustainable Development (ICASD) was founded by these groups to contribute to the development of modern agriculture (ICASD, 2012). Since this group started working in the Sanjiang Plain (SJP, located in Heilongjiang Province, the most north-eastern part of China) in 2005, lots of field campaigns have taken place and quite an amount of firsthand scientific data has been accumulated.

The SJP in Northeast China (located between $43^{\circ} 49^{\prime} \mathrm{N}$ to $48^{\circ} 27^{\prime} \mathrm{N}$ and $129^{\circ} 11^{\prime} \mathrm{E}$ to $135^{\circ} 05^{\prime} \mathrm{E}$ ) covers an area of 10.89 million ha, exceeding the size of the Netherlands almost by three times. It includes 23 administrative counties and 52 large-scale farms, each responsible for several 10000 ha. The average elevation of the SJP is about $45-80 \mathrm{~m}$ a.s.1.. It is an alluvial plain of the three rivers Heilong Jiang, Songhua Jiang and Wusuli Jiang. This region is classified as a temperate humid and subhumid continental monsoon climate with a mean annual temperature of $\sim 2.5^{\circ} \mathrm{C}$. Winter is long and cold with an average temperature of $-18^{\circ} \mathrm{C}$ in January, summer is short but with an average temperature of $21-22{ }^{\circ} \mathrm{C}$ in July (Yun et al., 2005). Annual precipitation ranges from 350 to $770 \mathrm{~mm}$, with about $80 \%$ occurring in May to September. The most typical soils are Luvisols, Phaeozems, Cambisols and Histosols (Huang, Y. et al., 2010).
The SJP is one of the most productive agricultural regions of China. Single-season rice is transplanted in late May and harvested in late September or early October (Zhang et al., 2012). Corn and soy bean are other main crops. The SJP plays an important role in guaranteeing the food security of China. It is a commercial food production base where most part of the yield is sold, both domestically and abroad.

There are two administrative systems in the study area. One is the general administrative system that specifies a Province County - Town-Village (PCTV) hierarchy, the other one is the Nongken administrative system with a Nongken Chief Bureau Administrative Farm - Farm-Village/Work Site (NAFV) hierarchy. Usually, several farms are located in one county, however, sometimes a farm is located not only in one but in two or more counties. Jiansanjiang city is the center city of the Jiansanjiang Administrative Farm, located in the northwest part of the Qixing Farm. Our experimental station was established in Jiansanjiang by the CAU and the local bureaus. The working group focuses on the area of the Qixing Farm $\left(1206 \mathrm{~km}^{2}\right)$, located within Fujin County $\left(8227 \mathrm{~km}^{2}\right)$.

Due to the intensive farming, especially the increase of rice paddy fields, environmental problems, including soil degradation and greenhouse gas emissions, become more and more important (Huang \& Song, 2010; Yan et al., 2003; Zhang et al., 2012). Spatially distributed agro-ecosystem modeling provides an important tool for analyzing agricultural sustainability under present and future conditions (LenzWiedemann et al., 2010). An AEIS for the North China Plain was successfully established and applied for ecosystem modeling such as the DNDC model (Bareth et al., 2002; 2005).

\footnotetext{
* Corresponding author.
} 


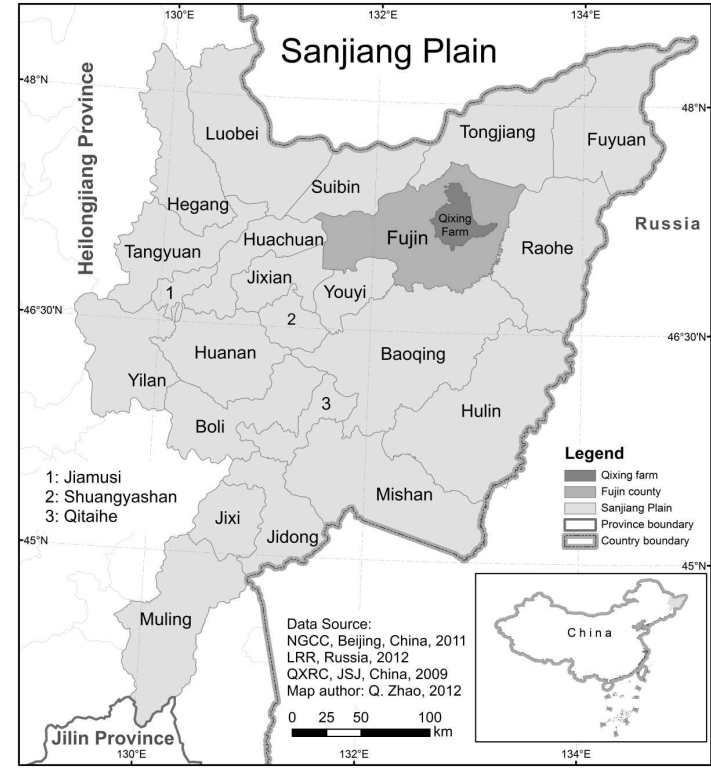

Figure 1. Location and counties of the SJP

The goal of this study is to set up an AEIS for the SJP for promoting sustainable agriculture. The AEIS is developed to provide information about agriculture in the region, to investigate the impact of agricultural practices on the environment, and to provide spatial input parameter for regional modeling approaches. Based on GIS, spatial data will be purchased, captured, stored, managed, analyzed, provided, and presented. Furthermore, regional modeling approaches will be linked to or integrated within the AEIS based on GIS technologies. Consequently, the AEIS for the SJP delivers information for spatial decision making and therefore could be regarded as a Spatial Decision Support System (SDSS) in a regional agricultural context (Bareth, 2009).

\section{SET UP OF THE AEIS}

For the implementation of an AEIS, parameters of atmosphere, hydrosphere and pedosphere that are related to crop growth such as climate data, $\mathrm{pH}$ value and soil texture are needed. Human activities like nitrogen fertilizer input, animal waste input, use of irrigation water and dates of sowing and harvest are important in an AEIS. These parameters are required for the modeling of the carbon- and nitrogen-cycles in agroecosystems. Proper methods for such data analysis and available agro-ecosystem models must be available. According to Bareth (2009) and Bareth and Yu (2002), an AEIS for sustainable agriculture includes six different information systems which are:

- $\quad$ Base Geo Data Information System (BGDIS)

- Soil Information System (SIS)

- Climate Information System (CIS)

- $\quad$ Land Use Information System (LUIS)

- Agricultural Management Information System (AMIS)

- Hydrological Information System (HIS)

In this study, macro, meso and micro scale are defined as following: macro scale: $\geq 1: 100000$; meso scale: from $<1: 100000$ to $>1: 1000000$; micro scale: $\leq 1: 1000000$.

\subsection{Base Geo Data Information System (BGDIS)}

The BGDIS is the core of the AEIS to provide different spatial levels in a holistic framework. A variety of unique spatial characteristics is utilized by the BGDIS to perform spatial analysis. Not only topographical datasets with detailed information such as roads, rivers, settlements etc., but also administrative boundary datasets both for the county boundaries in the PCTV system and for the farms in the NAFV system are needed. All these datasets should be in macro scale and either in vector or raster format.

In this study, one administrative county boundary vector dataset in an independent coordinate system was provided by the local official bureau. Unfortunately, the scale of this data is not clearly defined. Detailed boundary datasets both for the 23 counties and the 52 farms are needed and sub-units will be defined to solve the problem of overlapping county and farm areas. Detailed topographic datasets for Fujin County on a macro scale and for the whole SJP on a meso scale will be purchased from the National Geomatics Center of China (NGCC).

Many digital maps are available on the internet. The 1:4000 000 data for all of China is available for free on the NGCC website (NGCC, 2011). Websites such as the China Survey Data Network (CSDN, 2012) and the DIVA-GIS website (DIVA-GIS, 2012) provide lots of digital datasets. However, usually the scale of these datasets cannot satisfy our data requirements.

\subsection{Soil Information System (SIS)}

Soil parameters are very often the most sensitive input parameters in agro-ecosystem models. Spatial information on soils is necessary to target disaggregated agro-ecosystem modeling. A SIS is essential for providing agro-ecosystem model input parameters. Therefore, spatial soil information (e.g. $\mathrm{pH}$ value, soil texture and organic carbon content) in form of digital maps in macro scale or at multiple scale levels is needed.

\begin{tabular}{|l|l|l|}
\hline & Soil dataset A & Soil dataset B \\
\hline Data format & grid raster & vector shape file \\
\hline Projection & WGS84 & Albers \\
\hline $\begin{array}{l}\text { Spatial } \\
\text { resolution/scale }\end{array}$ & $1 \mathrm{~km}$ & $1: 200000$ \\
\hline $\begin{array}{l}\text { Soil } \\
\text { classification } \\
\text { system }\end{array}$ & $\begin{array}{l}\text { FAO-90 } \\
\text { (Nachtergaele et } \\
\text { al., 2008) }\end{array}$ & $\begin{array}{l}\text { Chinese Genetic Soil } \\
\text { Classification System } \\
\text { (Xi et al., 1998) }\end{array}$ \\
\hline $\begin{array}{l}\text { Data source and } \\
\text { years }\end{array}$ & $\begin{array}{l}\text { SNSGS, 1979- } \\
1985\end{array}$ & SNSGS, 1979-1985 \\
\hline Soil properties & $\begin{array}{l}\text { soil names; } \\
\text { e.g. soil texture, } \\
\text { bulk density, } \\
\text { pH value, SOM } \\
\text { (all in layers of } \\
0-30 \mathrm{~cm} \text { and } \\
30-100 \mathrm{~cm} \text { ) }\end{array}$ & soil names \\
& & \\
\hline
\end{tabular}

Table 1. Comparison of the soil data sets

In this study, 1:1 000000 soil data (soil dataset A) was provided by the Environmental and Ecological Science Data Center for West China, National Natural Science Foundation of China (EESDC, 2011). This data was sampled, analyzed and mapped during the Second National Soil General Survey (SNSGS) during 1979 to 1985 . Although the soil properties are very detailed, the scale is not accurate enough. One larger scale 
(1:200 000) digital soil dataset (soil dataset B) was provided by the China Wetland Scientific Database (CWSD, 2011). This data was digitized according to maps which were also generated from the SNSGS. In contrast to the soil dataset A, the soil properties are not so detailed, and the spatial resolution is not as large as expected (Table 1).

For our study, soil samples collected in the area of the Qixing Farm are used. From 2005 to 2007, more than 6000 soil samples were taken by the staff of the Qixing Farm in a depth of 0 to $20 \mathrm{~cm}$ distributed over the area of the Qixing Farm. This data and soil samples taken during our field campaigns will be used as a reference dataset.

\subsection{Climate Information System (CIS)}

The CIS provides the climate parameters for the agro-ecosystem modeling. Climate data should be available in daily or hourly temporal resolution, according to the model input data requirements. Weather maps with detailed information such as air temperature, precipitation, wind speed etc. are needed.

In this study, data of seven weather stations in the SJP was downloaded from the China Meteorological Data Sharing Service System (CMDSSS, 2011). All datasets dating back to 1951 have a daily resolution and include temperature, precipitation, air pressure, wind speed and directions, air moisture, etc.. Additionally, two books (written communication: Agricultural Bureau of Heilongjiang Nongken, 2003; Jiansanjiang Administrative Farm, 1998) were provided by the local weather information bureau. Here, daily weather information is provided from 1991 to 2000 for 82 farms in Heilongjiang Province, 47 of them are within the SJP. Both daily and hourly data in digital format was collected from the Jiansanjiang weather station (located in the northern part of the Qixing Farm) in 2011. The daily data was recorded from 2000 to 2010 , and hourly data from an automatic weather station covers 2010 to 2011 . In the last years, more automatic weather stations were installed which provide hourly data.

Climate maps will be generated using GIS interpolation methods within the AEIS. The number of weather station sites must be adequate enough to provide detailed information. Automatic weather stations can provide even minutely data and more accurate information. However, power cuts, occurring frequently in the intensive farming season, can significantly impair the data quality.

\subsection{Land Use Information System (LUIS)}

Land use provides a strong integrative tool for revealing agroecosystem patterns. The LUIS in the AEIS focuses on the arable land use. Detailed land use maps from different periods are required to reveal the farming patterns and investigate crop land changes. Ideally, the land use maps should not only give information about the major crops, but should differentiate between the different crop varieties and should contain crop rotations (Waldhoff et al., 2011).

In the present study, the 1:100 000 land use vector datasets for the years 1980s, 1995 and 2000 were purchased from the Data Center for Resources and Environmental Sciences, Chinese Academy of Sciences (RESDC, 2011). These land use maps are generated from satellite images provided by Landsat TM (Thematic Mapper) images from the 1980s, 1995/1996 and 1999/2000. The maps only give information about forest, cities, waters, grassland and arable land etc. on the county level, but not about crop type and variety which are needed for detailed agro-ecosystem modeling.

To solve the problem of lacking spatially disaggregated crop type data, remote sensing data and analyzes will be used and carried out. Similar approaches as described by Zhang et al. (2012) and Waldhoff et al. (2012) will be applied.

\subsection{Agricultural Management Information System}

Farm management data such as sowing/transplanting/fertilizing date, amount of nitrogen fertilizer input, irrigation management (especially for rice), plant protection management, harvest time, or special regime of management are provided by the AMIS. Information is needed both on county and farm level, in the PCTV and NAFV system.

In this study, original statistical data in the PCTV system on county level from 1950 to 2004 was provided by the Northeast Institute of Geography and Agroecology, Chinese Academy of Science, China Black Soil Ecology Database (CBSED, 2011). In these data sets, information on county level such as sowing area, chemical fertilizer input, yield of main crops etc. is given. For 2005 to 2011, the statistical data for the SJP is found in the Heilongjiang Statistical Yearbooks (Heilongjiang Statistical Bureau and Heilongjiang survey team from the National Bureau, 2006-2011), but some necessary information on county level is not given. Farmers' surveys about management data have taken place every year since our working group activities in the study area started in 2005. More detailed statistical data covering 2005 to 2011 on county level in the PCTV system is needed and statistical data on the farm level in the NAFV system has to be organized. For the site-specific study area of Qixing Farm, farmers' surveys will be carried out during our field campaigns in the future.

For the AEIS, more digital maps will be generated from the available statistical data. Local bureaus such as the Heilongjiang Nongken Statistical Information Bureau will be contacted.

\subsection{Hydrological Information System}

Hydrological characteristics are essential for the agricultural production, especially in a rice dominated farming area such as the SJP. An HIS provides the information about the water balance cycle in the region and its basic processes, such as precipitation, interception, evapotranspiration, water flow in soils, ground water, surface runoff, interflow, ground flow, stream flow etc.. Long-term hydrological data can be acquired according to the records of the local water conservancy bureaus. Site-specific hydrological information monitoring campaigns and remote sensing methods can also be applied (Bareth et al., 2009). For the SJP, until now very little efforts were spent on such data acquisition. Consequently, the HIS for the SJP is a task for the near future.

\section{RESULTS}

First results of integrating various spatial and statistical datasets in the AEIS for the SJP are presented here. The value of visualizing multitemporal statistical information on agriculture lies in giving important knowledge on the land use history and on the land use change in the study region. Both are important to better understand the matter fluxes in the given context. 


\subsection{Paddy land use change from the 1980s to 2000}

Based on the 1:100 000 land use vector datasets for the years 1980s and 2000 (RESDC, 2011), the land use change map for paddy fields (Fig. 2) was generated. Most of the counties in the SJP show a high increase in paddy land use except for Raohe County with a decrease and Muling County with no change. Almost all the counties in the northern part of the SJP show an increase of more than $100 \%$. In Suibin and Jixian County, the increment is even more than 20 times. In the southern part of the SJP, most counties show an increase of less than $50 \%$. In the counties of Yilan, Shuanyashan, Boli and Qitaihe, an increase between 50 and $100 \%$ occurred. In Hulin County, also located in the southern part, the increase even exceeds $1000 \%$.

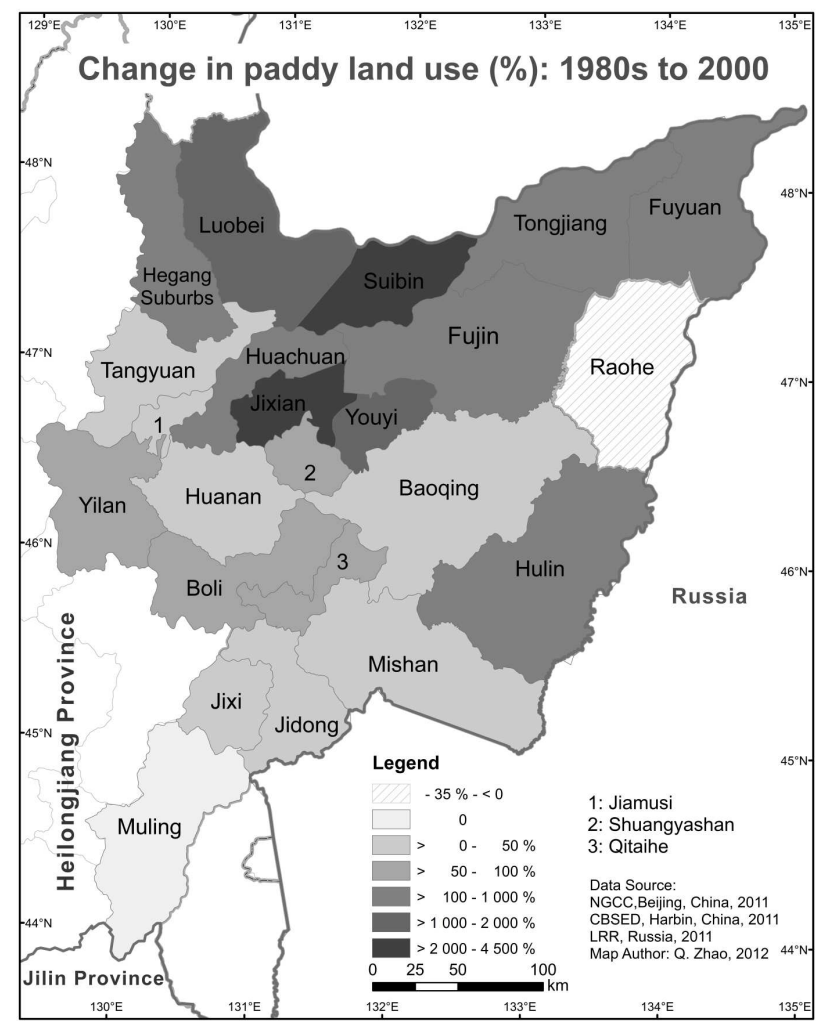

\subsection{Land use change for representative counties from the 1980 s to 2000}

Table 2 shows the land use change for the two periods from the 1980s to 1995 and from 1995 to 2000 . Considering the whole SJP, paddy land area decreased by $28.3 \%$ in the first period, and sharply increased by $157.2 \%$ in the second period. On the contrary, the area of dryland increased by $14.6 \%$ in the first period and decreased by $7.7 \%$ in the second period. The grassland at first dramatically decreased by $45 \%$ and then increased only by $2.4 \%$. The area of wetland decreased all over the years, with a decline of more than $10 \%$ for each period. The other land use classes did not change as much in total. For example, in Fujin County, a 1.6-fold increase for paddy land and $9.5 \%$ for dryland occurred from 1995 to 2000. On the other hand, both grassland and wetland sharply decreased in these years. In Yilan County, from 1980s to 1995, dryland increased and paddy fields decreased. At the same time, grassland decreased by more than half whereas wetland slightly increased. For the following five years until 2000, paddy fields show a high increase. Dryland decreased, accompanied by a more than $10 \%$ decrease of wetland and $9.9 \%$ increase of grassland.

\subsection{Total sown area (TSA) from 1950 to 2010}

The development of the TSA for the non-farm area in the SJP during the last 60 years is shown in Fig. 3. Overall, the TSA increased strongly from 1950 to 2010 . In 1950, the TSA was less than 20000 ha in most counties. However, until 2010 it increased to more than 150000 ha in one third of the counties. In the first 15 years, most of the counties showed an increase. In 1965 , the TSA in 19 counties was already more than 20000 ha. In e.g. Baoqing County, the TSA increased by more than 3.5 times. In the following 15 years from 1965, the increase was less pronounced. Many counties, e.g. Luobei, Suibin and Mishan County, even show a loss in TSA. Although it is not clearly to be seen in the map due to the classification, the TSA rose from 1980 to 1994 . From 1994 to 2004, the TSA in each county increased rapidly. It reached more than 150000 ha in Fujin, Baoqing, Huanan and Yilan County. From 2004 to 2010, the TSA continued to increase strongly. Now, in more than a half of the SJP counties, the TSA exceeds 70000 ha.

Figure 2. Change in paddy land use (\%) from the 1980 s to 2000

\begin{tabular}{|c|c|c|c|c|c|c|c|c|c|c|}
\hline \multirow[b]{3}{*}{ Time } & \multicolumn{10}{|c|}{ Land use change (\%) } \\
\hline & \multicolumn{2}{|c|}{ Paddy field } & \multicolumn{2}{|c|}{ Dryland } & \multicolumn{2}{|c|}{ Grassland } & \multicolumn{2}{|c|}{ Wetland } & \multicolumn{2}{|c|}{ Others } \\
\hline & $\begin{array}{c}1980 \mathrm{~s} \\
\text { to } 1995\end{array}$ & $\begin{array}{c}1995 \\
\text { to } 2000\end{array}$ & $\begin{array}{c}\text { 1980s to } \\
1995\end{array}$ & $\begin{array}{c}1995 \\
\text { to } 2000\end{array}$ & $\begin{array}{c}\text { 1980s to } \\
1995\end{array}$ & $\begin{array}{c}1995 \\
\text { to } 2000\end{array}$ & $\begin{array}{c}1980 \mathrm{~s} \\
\text { to } 1995\end{array}$ & $\begin{array}{c}1995 \\
\text { to } 2000\end{array}$ & $\begin{array}{c}\text { 1980s to } \\
1995\end{array}$ & $\begin{array}{c}1995 \\
\text { to } 2000\end{array}$ \\
\hline Baoqing & -88.5 & 1097.7 & 73.8 & -40.3 & -18.3 & -17.0 & -24.9 & -11.2 & -1.1 & -3.8 \\
\hline Luobei & 216.9 & 550.7 & 15.4 & -28.6 & -47.5 & 15.5 & -27.3 & -8.3 & 0.3 & -3.1 \\
\hline Mishan & -56.6 & 185.4 & 24.3 & -13.5 & -2.9 & -38.2 & -7.4 & -14.9 & 3.5 & -6.6 \\
\hline Fuyuan & 6.5 & 161.9 & 61.5 & 9.5 & -89.3 & -87.6 & -7.3 & -7.4 & 10.7 & -1.4 \\
\hline Hulin & 18.6 & 145.7 & 45.0 & -4.9 & -70.3 & 33.5 & -3.0 & -22.2 & 7.5 & -2.2 \\
\hline Yilan & -14.9 & 80.5 & 11.6 & -10.0 & -54.9 & 9.9 & 4.2 & -11.3 & -0.6 & -1.0 \\
\hline Huachuan & 61.0 & 73.2 & -7.3 & -12.7 & 280.6 & -6.0 & 4.6 & -56.3 & -16.1 & -4.5 \\
\hline Tangyuan & -13.5 & 62.4 & 8.9 & -14.8 & 16.6 & -37.7 & 70.9 & -41.5 & -9.8 & 9.2 \\
\hline Fujin & 99.1 & 43.3 & 3.6 & -0.2 & -29.8 & 23.6 & -8.3 & -3.8 & 1.3 & -0.7 \\
\hline Youyi & 1204.4 & 42.4 & 2.6 & 3.1 & 33.9 & -25.3 & -45.0 & -44.3 & 5.8 & -0.5 \\
\hline Muling & -22.3 & 28.7 & -3.2 & 10.4 & 3.6 & -2.5 & no wetland & no wetland & 1.8 & -3.7 \\
\hline Total change & -28.3 & 157.2 & 14.6 & -7.7 & -45.0 & 2.4 & -11.3 & -10.6 & 1.6 & -3.9 \\
\hline
\end{tabular}

Table 2. Land use change (\%) for selected classes from the 1980s to 2000 in the SJP for the representative counties 


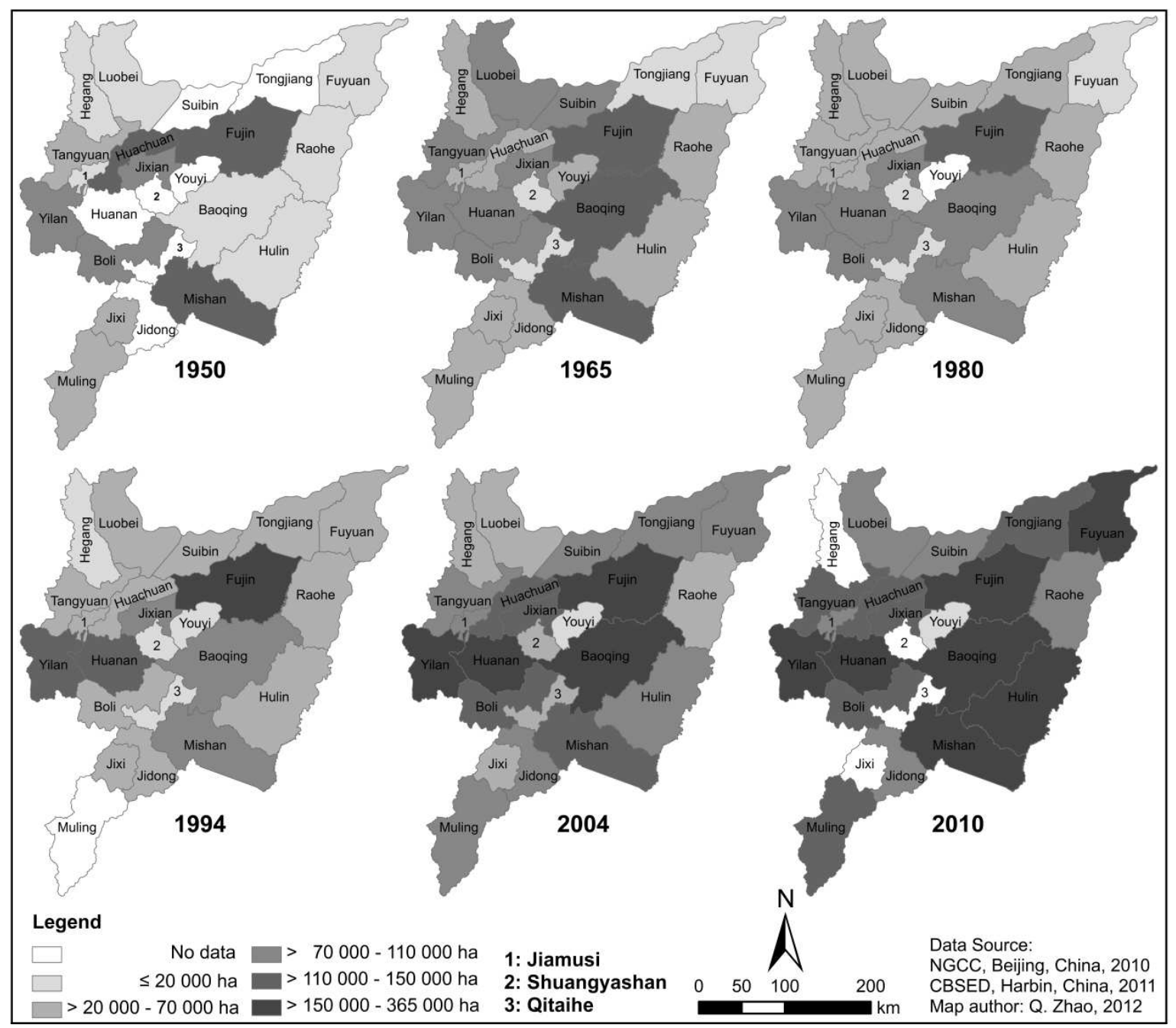

Figure 3. Total sown area of the non-farm area in the SJP for the last 60 years

\section{DISCUSSION AND CONCLUSIONS}

Land use change of paddy rice shown in Fig. 2 reveals similar results compared with the study by Chen et al. (2012). Due to climate warming in Heilongiiang starting in the 1980 s, the sown area of rice increased strongly (Guo, 2003; Yun, 2005). However, a severe problem for rice growth in the region is cold damage which happens frequently (Zhang et al. 1991). In general, rice produces higher yields than e.g. soy bean but is more temperature sensitive. Consequently, farmers changed the crop type from year to year.

In Muling County, the most southern one of the SJP (Fig. 1), farmers first cultivated a large area of paddy fields in the early years of the 1980s because of the increasing temperature. After several colder years, they changed some of the paddy land into dryland, then again changed back to paddy fields (from 2198 ha in the 1980s to 17025 ha in 1995 and back to 2198 ha in 2000). From Tab. 2, it can be easily derived that the paddy land was mainly converted from dryland and wetland, since the other land use classes did not change significantly. The increase of dryland is mainly due to conversion from grassland in the period of the 1980 s to 2000 .

The change of the TSA during the last 60 year in Fig. 3 shows a special trend. The TSA increased very much in the first 15 years. After the establishment of the new China in 1949, people focused on the agricultural production: New farming fields were reclaimed in a short time. From 1965 to 1980 , the TSA did not increase very much. In the 1980 s, the focus was on increasing yield, not on reclaiming more agricultural land. From 1994 to 2004 , the reclamation of arable land occurred under pressure of increasing population and food demand. With the availability of new technologies, it was possible to manage larger areas. The TSA increased rapidly in the six years from 2004 to 2010.

The AEIS for the SJP will be used to investigate the long-term change of the agro-ecosystems, to provide data sets for ecosystem modeling and to derive sustainable management strategies. It was possible to integrate first basic datasets in the AEIS for the SJP. The main difficulty in establishing an AEIS is the acquisition of available detailed soil data which is demanded for spatially distributed agro-ecosystem modeling, of detailed management data, as well as of detailed land use maps which differentiate between the different crops within arable land.

\section{REFERENCES}

Bareth, G., 2009. GIS- and RS-based spatial decision support: structure of a spatial environmental information system (SEIS). International Journal of Digital Earth, 2(2), pp. 134-154. 
Bareth, G. and Yu, Z., 2002. Agri-Enviro Information System for the North China Plain. Proceedings of the ISPRS Commission II Symposium of Integrated Systems for Spatial Data production, Custodian and Decision Support, Xi'an, China, Vol. XXXIV, Part 2 II, pp. 23-29.

Bareth, G. and Yu, Z., 2005. Interfacing GIS with a process based agro-ecosystem model - case study North China Plain. Proceedings of the International Symposium on Spatiotemporal Modelling, Spatial Reasoning, Spatial Analysis, Data Mining and Data Fusion, Peking University, China, Vol. XXXVI, Part 2/W25, pp. 69-74.

CBSED, 2011. http://www.neigae.blackland.csdb.cn (15 Aug. 2011).

Chen, C., Qian, C., Deng, A. and Zhang, W., 2012. Progressive and active adaptations of cropping system to climate change in Northeast China. Eur J Agron, 38, pp. 94-103.

CMDSSS, 2011. http://cdc.cma.gov.cn (20 Dec. 2011).

CSDN, 2012

http://www.chinasurveycenter.org/CSDN_EN/default.aspx (2 Feb. 2012).

CWSD, 2011. http://www.marsh.csdb.cn (12 Sep. 2011).

DIVA-GIS, 2012. http://www.diva-gis.org (1 Mar. 2012).

EESDC, 2011. http://westdc.westgis.ac.cn (10 Jan. 2011).

Guo, S., Zou, L. and Wu, Q., 2003. Climate change characteristics in nearly one century in Heilongjiang Province. Heilongjiang Meteorology, 2003(4), pp. 8-11 (in Chinese with English abstract).

Heilongjiang Statistical Bureau and Heilongjiang survey team from the National Bureau, 2006-2011. Heilongjiang Statistical Yearbook 2005 - 2010. Harbin, China.

Huang, J. and Song, C., 2010. Effects of Land use on soil water soluble organic $\mathrm{C}$ and microbial biomass $\mathrm{C}$ concentrations in the Sanjiang Plain in northeast China. Acta Agr Scand B-S P, 60 , pp. $182-188$.

Huang, Y., Sun, W., Zhang, W., Yu, Y., Su, Y. and Song, C., 2010. Marshland conversion to cropland in northeast China from 1950 to 2000 reduced the greenhouse effect. Glob Change Biol, 16, pp. 680-695.

ICASD, 2012. http://www.icasd.org (22 Mar. 2012).

Lenz-Wiedemann, V.I.S., Klar, C.W. and Schneider, K., 2010. Development and test of a crop growth model for application within a Global Change decision support system. Ecol Model, 221(2), pp. 314-329.

LRR, 2012

http://www.iiasa.ac.at/Research/FOR/russia_cd/download.htm (20 Nov. 2011)
Nachtergaele, F., Velthuizen, H. and Verelst, L., 2008. World Soil Database, Food and Agriculture Organization of the United Nations, pp. 1-38.

NGCC, 2011. http://nfgis.nsdi.gov.cn (10 Jan. 2011).

QXRC, 2009. Qingxing Research Center, Qixing Farm, Jiansanjiang, Heilongjiang Province, China.

RESDC, 2011. http://www.resdc.cn/first.asp (22 Mar. 2011).

Waldhoff, G., Curdt, C., Hoffmeister, D. and Bareth, G., 2012. Analysis of multitemporal and multisensor sensing data for crop rotation mapping. Proceedings of the XXII Congress of the ISPRS, Melbourne, Australia, (accepted).

Waldhoff, G., Curdt, C., Hoffmeister, D. and Bareth, G., 2011. Spatio-temporal land use patterns for regional (agro-) ecosystem modeling. Proceedings of the International Symposium on remote sensing and GIS methods for change detection and spatio-temporal modelling (CDSM), Hong Kong, China, pp. 15-16.

Xi, C., Zhu, K., Zhou, M., Du, G., Li, X., Zhang, S., Yang, B., Hou, C., Tang, J. and Zhou, C., 1998. Soils of China, Chinese Agriculture Press, Beijing, pp. 1-1253, in Chinese.

Yan, M., Deng, W. and Chen, P., 2003. Recent trends of temperature and precipitation disturbed by large-scale reclamation in the Sanjiang Plain of China. Chinese Geogr Sci, 13(4), pp. 317-321.

Yun, Y., Fang, X., Wang, Y., Tao, J. and Qiao, D., 2005. Main grain structural change and its climate background in Heilongjiang Province during the past two decades. Journal of Natural Resources, 20(5), pp. 697-705 (in chinese with English abstract).

Zhang, Y., He, W. and Li, S., 1991. Introduction to China Meteorological Disasters. Meteorological Press, Beijing, China http://book.chaoxing.com/ebook/read_10655167.html, (5 Apr. 2012, in Chinese).

Zhang, Y., Su, S., Zhang, F., Shi, R. and Gao, W., 2012. Characterizing Spatiotemporal Dynamics of Methane Emissions from Rice Paddies in Northeast China from 1990 to 2010. PLoS ONE, 7(1), e29156 (20 Mar. 2012).

\section{ACKNOWLEDGEMENTS}

The author is supported by the China Scholarship Council (Nov. 2010 - Oct. 2014), Beijing, China. This work is funded by the International Bureau of the German Federal Ministry of Education and Research (BMBF, project no. 01DO12013), the German Research Foundation (DFG, project no. BA 2062/8-1), the Qixing Research and Development Centre and the Jiansanjiang Agricultural Research Station, both in Heilongjiang, China. The statistical data for the non-farm area in the SJP from 1950 to 2004 was provided by Northeast Institute of Geography and Agroecology, Chinese Academy of Sciences, China Black Soil Ecology Database. The land use datasets were provided by the Data Center for Resources and Environmental Sciences, Chinese Academy of Sciences. 